\title{
MICROFARMS: ANÁLISE DA COMPLEXIDADE TECNOLÓGICA E CUSTOS PARA A CRIAÇÃO DE MICROFAZENDAS PARA PRODUÇÃO DE ALIMENTOS
}

\author{
Ricardo Antonello \\ Instituto Federal Catarinense \\ ricardo.antonello@luzerna.ifc.edu.br \\ Ciro Nagel de Marco \\ Instituto Federal Catarinense \\ ciro.nagel@gmail.com
}

\author{
Thiago Dalmedico Flores \\ Instituto Federal Catarinense \\ thiagodalmedicoflores@gmail.com \\ Haroldo Gegório de Oliveira \\ Instituto Federal Catarinense \\ haroldo.oliveira@luzerna.ifc.edu.br
}

\begin{abstract}
Resumo
Este trabalho apresenta um relato de experiência de um estudo envolvendo a análise da complexidade tecnológica e custos para a criação de microfazendas para produção de alimentos. A tecnologia estudada envolveu a técnica de hidroponia para o cultivo de hortaliças. Para a automação da microfazenda foi estudada a tecnologia Open-Hardware Arduíno. Foram estudados aspectos relacionados a automação do controle dos nutrientes, da iluminação e do controle de variáveis do ambiente como a temperatura. Como resultado concluímos que a um baixo custo é possível criar uma microfazenda para produção de alimentos utilizando técnicas hidropônicas. A criação do protótipo e testes são sugeridos para trabalhos futuros.
\end{abstract}

Palavras-chave: Arduíno. Hidroponia. Microfazenda.

\section{MICROFARMS: COMPLEXITY ANALYSIS OF TECHNOLOGICAL AND COST FOR MICROFARMS FOR FOOD PRODUCTION}

Abstract

This paper presents an experience report of a study involving the analysis of technological complexity and costs for creating microfarms for food production. The study involved hydroponics technique for growing vegetables. For the automation of microfarm been studied Open-Hardware Arduino technology. They studied aspects related to automation of the control of nutrients, lighting and environmental control variables such as temperature. As a result we conclude that a low cost it is possible create a microfarm for food production using hydroponic techniques. The creation of the prototype and tests are suggested for future work.

Keywords: Arduino. Hydroponics. Microfarm.

\section{MICROFARMS: ANÁLISIS DE LA COMPLEJIDAD TECNOLÓGICA Y CUSTOS PARA LA CRIACIÓN DE MICROFAZENDAS PARA LA PRODUCCIÓN DE ALIMENTOS}

Resumen

Este artículo presenta un relato de experiencia de un estudio que incluyó el análisis de la complejidad tecnológica y los costes para la creación de microgranja para la producción de alimentos. El estudio incluyó a los cultivos hidropónicos de tecnología para el cultivo de hortalizas. Para la automatización de microgranja ha estudiado la tecnología Arduino abierto en hardware. Se estudiaron los aspectos relacionados con la automatización del control de variables de nutrientes, iluminación y control del medio ambiente, tales como la temperatura. Como resultado llegamos a la conclusión de que un bajo costo puede crear un microfazenda para la producción de alimentos mediante técnicas hidropónicas. La creación del prototipo y pruebas se sugieren para el trabajo futuro.

Palabras clave: Arduino. Hidroponía. Microgranja. 
Microfarms: análise da complexidade tecnológica e custos para a criação de microfazendas para produção de alimentos

\section{INTRODUÇÃO}

A agricultura voltada para a produção de alimentos vem sendo influenciada fortemente pela mecanização e pela tecnologia. A evolução tecnológica esta abrindo os horizontes da pesquisa do design contemporâneo em um ritmo acelerado dentro do campo da produção de alimentos. Apesar disso, diversas regiões do mundo enfrentarão problemas para realizar a expansão de áreas destinadas à agropecuária. Além da falta de espaço físico, solo com baixa fertilidade e fontes escassas de água serão obstáculos para a produção de alimentos no futuro, cita um relatório da Organização das Nações Unidas (ONU, 2015). Nesse sentido, a preocupação com a produção de alimentos é um tema extremamente relevante na atualidade.

Neste cenário um novo conceito emerge. Uma microfazenda é uma estrutura reduzida para a produção de alimentos através de técnicas de hidroponia. Uma microfazenda, além de pequena é portátil e pode ser instalada em qualquer residência para a produção de alimentos como alface, agrião, rúcula, escarola, salsa, cebolinha, coentro, dentre outros. O tempo de cultivo varia de acordo com o tipo da planta mas é possível misturar em uma mesma microfazenda tipos diferentes de plantas, principalmente no caso de ser automatizada, ou seja, possuir gerenciamento inteligente da produção.

A um custo muito baixo é possível cultivar hortaliças dentro do mais alto padrão de higiene e qualidade e com toda a confiança já que as sementes utilizadas são as mesmas do cultivo tradicional. Além disso, a economia de água chega a 70\% em relação ao método tradicional (ALBERONI, 1998) e não se utiliza nenhum agrotóxico no processo, permitindo a colheita de um produto final totalmente saudável.

Neste trabalho, apresentamos um relato da experiência obtida no estudo, projeto e prototipagem de uma microfazenda para produção de alimentos. O relato inclui o compartilhamento da dos estudos de técnicas do cultivo de alimentos através da hidroponia e das tecnologias necessárias de controle e automação para criação da microfazenda. Este trabalho foi desenvolvido através de um projeto de extensão dos alunos do curso EMITAI - Ensino Médio Integrado em Automação Industrial do Instituto Federal Catarinense - IFC, visando propor um projeto de microfazenda totalmente automatizado para o cultiva de alimentos.

Em "Resultados e Análises” apresentamos um projeto e protótipo de uma estufa que compõe o projeto bem como o projeto da automação com microcontroladores, sensores e atuadores, já que variáveis como temperatura, $\mathrm{pH}$ e quantidade de nutrientes da água devem ser mensurados e gerenciados, tornando mínima a necessidade de intervenção humana no processo de produção dos alimentos. 
Microfarms: análise da complexidade tecnológica e custos para a criação de microfazendas para produção de alimentos

O projeto se caracteriza como extensão já que foi desenvolvido em parceria com um produtor rural utilizador das técnicas de hidroponia e, apesar de não corresponder ao escopo atual deste trabalho, a parceria com o produtor abaixo citado gerou novos trabalhos destacados em "Resultados e Análises".

\section{MATERIAIS E MÉTODOS}

A pesquisa experimental foi a base dos estudos. Para tanto, foi utilizado o método dedutivo, utilizando-se também da pesquisa bibliográfico documental e o método experimental.

Inicialmente foram estudadas as tecnologias Arduíno e Raspberry Pi que podem ser utilizadas para controlar todos os sensores e atuadores da microfazenda. Além disso, paralelamente, foram iniciados contatos com produtores que utilizam a técnica da hidroponia na região. Vencida a etapa inicial de estudos e busca de informações iniciou-se o processo de projeto para o protótipo. Após a finalização dos projetos foi iniciada a criação do protótipo conforme poderemos ver no item "Resultados e Análises".

O grupo de trabalho, constituído por alunos do Ensino Médio Integrado ao Curso Técnico em Automação Industrial do Instituto Federal Catarinense - IFC, Campus Luzerna realizou cada uma das etapas listadas a seguir: foram Estudo de técnicas de hidroponia; criação de projeto de automação para microfazenda; criação de projeto físico para microfazenda; geração de artigo com conhecimentos adquiridos e relato de experiência.

\section{RESULTADOS E ANÁLISES}

Abaixo apresentamos os resultados e análises decorridas dos trabalhos realizados no projeto apresentado. Foi realizado um levantamento envolvendo a analise da complexidade tecnológica e custos para a criação de microfazendas para produção de alimentos. A tecnologia estudada envolveu a técnica de hidroponia para o cultivo de hortaliças. Para a automação da microfazenda foi estudada a tecnologia Open-Hardware (OSHW, 2015) Arduíno (ARDUÍNO, 2015). Foram estudados aspectos relacionados a automação do controle dos nutrientes, da iluminação e do controle de variáveis do ambiente como a temperatura. Como resultado concluímos que a um baixo custo é possível criar uma microfazenda para produção de alimentos 
Microfarms: análise da complexidade tecnológica e custos para a criação de microfazendas para produção de alimentos

utilizando técnicas hidropônicas. A criação do protótipo e testes são sugeridos para trabalhos futuros.

Logo no início dos trabalhos, procuramos fontes bibliográficas sobre hidroponia. Albertoni (1998) e Douglas (1987) foram nossas principais referências quanto a definição sobre hidroponia. A hidroponia consiste em uma técnica de fornecer os nutrientes necessários para o desenvolvimento da planta de forma rápida e higiênica. Conforme Douglas (1987) a hidroponia é diferente da agricultura orgânica. O principal motivo é que ela é formada basicamente por um sistema hidropônico, e como tal, não utiliza o solo, e também, porque produz plantas altamente sãs, e com elevado nível de assepsia. Algumas de suas vantagens são, não agride o meio ambiente, pois todos os materiais são reciclados, e seu processo é mais prático, o número de pragas é extremamente pequeno, portanto não é necessário o uso de pesticidas sintéticos. Albertoni (1998) ainda informa que a hidroponia não é um processo "totalmente" orgânico pois ainda há utilização de fertilizantes químicos. O mesmo encontramos em Mundo Orgânico (2015) que informa que hidroponia não é uma produção "orgânica", contudo, não significa que faz mal a saúde ou que é prejudicial. Uma outra referência muito importante para este trabalho foram os estudos do LabHidro (2015) conforme site oficial do projeto desenvolvido dentro da Universidade Federal de Santa Catarina - UFSC. As informações contidas no site oficial do LabHidro foram fundamentais para o grupo de estudos deste projeto.

Sempre com o foco extensionista presente na equipe do trabalho, logo no início das atividades realizamos nas dependências do Instituto Federal Catarinense - IFC, Campus Luzerna, uma reunião com o coordenador do programa de inovação do campo da Epagri, escritório regional de Joaçaba - SC. O contato com a Epagri e a posterior reunião, visou estabelecer parceria para este projeto já que a Epagri atua com pesquisas na área agrícola e possui contatos e parcerias com produtores que fazem uso da hidroponia.

A reunião foi produtiva sendo que foram compartilhados contatos de produtores locais de culturas hidropônicas. O mais próximo do Campus Luzerna do IFC para visitação foi o produtor Valério Stella. Dessa forma, foi realizado contato telefônico com o filho do Sr. Valério Stella, Maycon Stella, que é agrônomo e aceitou nos receber o grupo de trabalho na propriedade onde são produzidas as culturas. Desta visita, já adiantou pelo telefone, é possível que surja outra parceria, já que a propriedade rural carece de mecanismos de automação para o processo de cultivo hidropônico.

$\mathrm{Na}$ visita o grupo de trabalho compareceu a propriedade Stella no distrito de Santa Clara, município de Joaçaba - SC. Durante a visita Maicon Stella e Fabio Stella que são filhos de Valério Stella acompanharam a visitação. Maicon é agrônomo e, portanto, possui bagagem teórica além 
Microfarms: análise da complexidade tecnológica e custos para a criação de microfazendas para produção de alimentos

da prática do dia a dia. Seu irmão Fabio, também se especializou com vários cursos na área de hidroponia, informaram que anualmente fazem cursos de reciclagem no LabHidro (2015) da UFSC.

A propriedade possui 150 sistemas de irrigação/bombeamento cada um com uma caixa d'agua de 100 litros. Existem propriedades onde a sistema de onde sai a solução hidropônica é todo interligado, mas no caso da propriedade Stella o sistema é separado pois isso diminui o risco de contaminação e reduz significativamente as perdas caso a contaminação apareça.

Como os 150 sistemas são separados, diariamente os produtores acessam as 150 caixas d'água para analisar o Ph e a condutividade elétrica da água. Baseado na condutividade é calculada a quantidade de nutrientes (sais minerais) na água e com base nesse cálculo é liberada a solução nutritiva concentrada de forma manual em cada caixa visando complementar e balancear a solução nutritiva.

Existem várias possibilidades de automação desse processo, e ficou acordado que o próximo projeto na área será um protótipo visando medir a condutibilidade elétrica da água e automaticamente liberar a solução de nutrientes concentrada na caixa d'água, evitando o acompanhamento manual diário.

Dessa forma o grupo de trabalho do projeto iniciou os processos de busca de equipamentos, sensores e válvulas além dos estudos iniciais para a programação de microcontroladores acessíveis para comandar os sistemas. Como o grupo de trabalho era composto por alunos do $1^{\circ}$ ano do Ensino Médio Integrado ao curso Técnica em Automação Industrial foram necessárias construções das bases de conhecimento da tecnologia Arduíno que seria utilizada no projeto, esses resultados observamos a seguir.

\section{Sistema de controle utilizando Arduíno}

Abaixo está o material produzido durante a fase de estudos e pesquisa bibliográficodocumental, bem como as notas e apontamentos, algoritmos intermediários e algoritmos de testes que criamos durante o método experimental.

Os estudos e a programação dos microcontroladores Arduíno foram realizados baseados em modelos simples de programação para que os participantes do projeto iniciassem os estudos nesta tecnologia Open Hardware (OSHW, 2015) conforme imagem abaixo: 
Microfarms: análise da complexidade tecnológica e custos para a criação de microfazendas para produção de alimentos

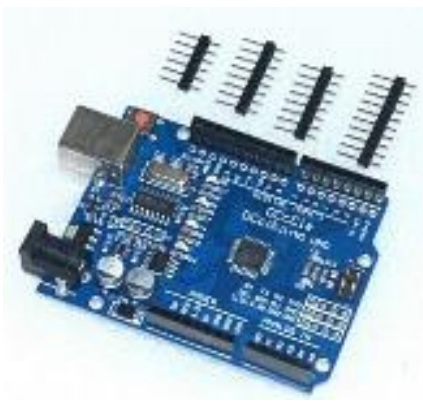

Ilustração 1 - Placa Arduíno. Fonte: Arduíno (2015).

No primeiro de projeto, foi feita a montagem de uma circuito com Arduíno para realizar a ligação de um LED e deixa-lo piscando em diferentes velocidades. A idéia deste exercício era exercitar o ambiente Arduíno para gravação de programas no microcontrolador da placa, bem como a linguagem $\mathrm{C}$, necessários para os projetos. Os componentes utilizados foram 1 resistor de 820 ohms; 1 LED; 2 fios de cobre; 1 placa Arduíno UNO; 1 cabo USB.

Montagem do circuito:

1 - Ligar o protoboard ao GND da placa Arduíno com um fio de cobre.

2 - Ligar o protoboard à entrada "13" da placa Arduíno com um fio de cobre.

3 - Conectar a polaridade negativa do LED ao GND, e a positiva ao resistor, que deve estar ligado a entrada "13” da placa Arduíno UNO.

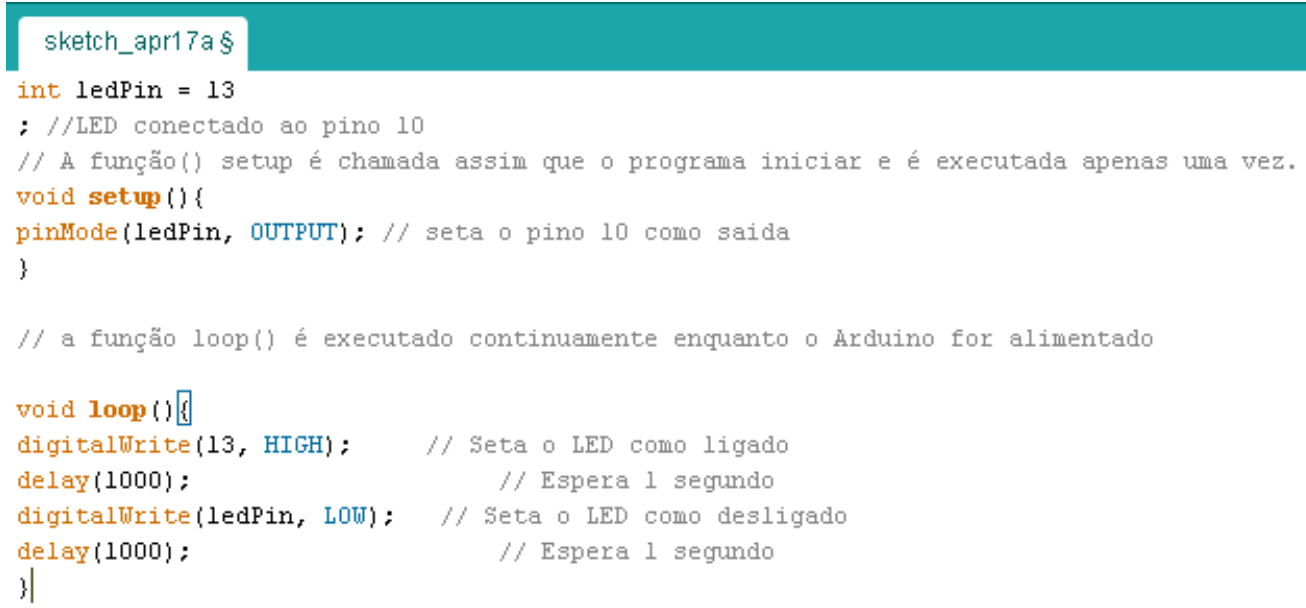

Ilustração 2 - Programação do Arduíno - Arduino IDE 1.0.5. Fonte: elaborado pelos autores.

Devido ao tipo de placa Arduíno que se estava utilizando, não foi possível codificar o programa (skech) no microcontrolador do Arduíno porque o driver para Windows 7 não estava 
Microfarms: análise da complexidade tecnológica e custos para a criação de microfazendas para produção de alimentos

reconhecendo a placa. Dessa forma foi necessário a atualização do driver no sistema operacional. O driver utilizado bem como a imagem da atualização seguem abaixo:

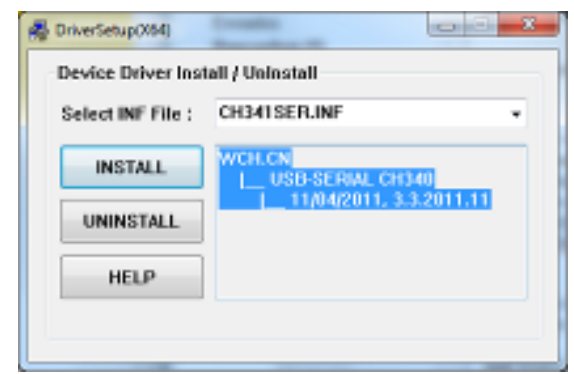

Ilustração 3 - Atualização de driver para Arduíno. Fonte: elaborado pelos autores.

Após a resolução do problema do driver descrito acima, foi finalizada a montagem do circuito conforme abaixo:

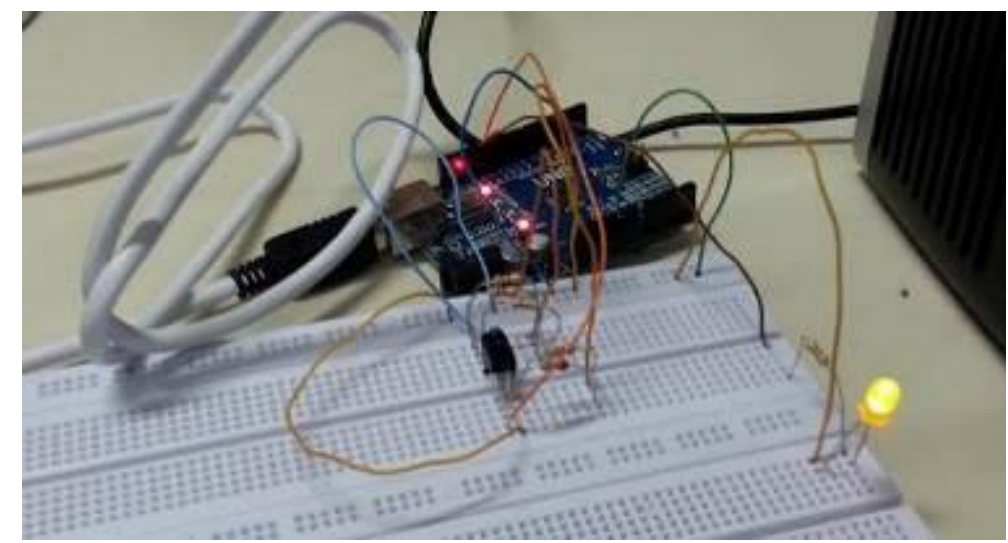

Ilustração 4 - Demonstração do Arduíno controlando uma variável (LED). Fonte: elaborado pelos autores.

Esse estudo iniciou um processo extenso de pesquisas e novos projetos de programação utilizando o microcontrolador. Isso foi fundamental para dominar a tecnologia Arduíno e poder utilizá-la para o controle de sensores de temperatura, luminosidade e $\mathrm{Ph}$ e condutividade elétrica conforme veremos abaixo. Como exemplo, o mesmo comando dado para ligar um LED é utilizado para ligar um ventilador que será acionado com base na temperatura lida dentro da microfazenda.

Os estudos que se seguiram deram conta de encontrar códigos e testes para sensores de temperatura, e luminosidade.

Já para $\mathrm{Ph}$ e condutividade elétrica não foram encontrados no mercado brasileiro sensores de baixo custo, sendo os mais acessíveis a preço de mais de $\mathrm{R} \$ 400,00$ (quatrocentos reais). Dessa forma, já que o projeto é apoiado com recursos internos do Campus do IFC Luzerna apenas para bolsas de pesquisa aos alunos, não foi possível comprar os sensores para o protótipo final. Visando dar continuidade ao projeto foi criado um esquema de produção de um 
Microfarms: análise da complexidade tecnológica e custos para a criação de microfazendas para produção de alimentos

sensor de condutividade elétrica cuja implementação ficou sugerida para trabalhos futuros. De maneira alternativa os membros do projeto compraram com seus próprios recursos outros itens visando criar um protótipo funcional para testar o controle das variáveis de temperatura e luminosidade.

\section{Projeto do sensor de condutividade elétrica}

Após uma vasta procura, encontramos um componente chamado de Célula de Condutividade, a qual consiste em duas placas metálicas que são fixadas e montadas em material isolante, que pode ser vidro ou plástico. Serve para delinear um pequeno volume constante do líquido e torna a medição da condutividade independente do volume total da amostra e da proximidade de superfícies ou paredes dos tanques ou tubulações. Os eletrodos são construídos de metal, geralmente platina, e são revestidas por um depósito eletrolítico de negro de platina. Isso limita os efeitos da polarização. O produto encontrado encontra-se disponível em Analion (2015), segue imagem abaixo:

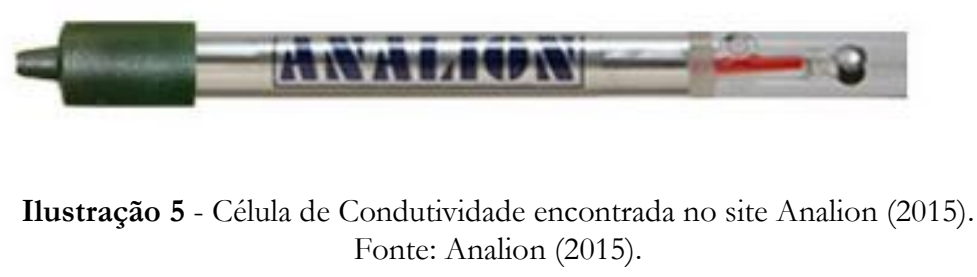

Dado o alto custo dos sensores diponíveis no mercado nacional, os membros do grupo de pesquisa buscaram outros sensores de baixo custo visando estabelecer um parâmetro de controle e testes futuros, apesar dos sensores não permitirem a conexão com o Arduíno. Os ensaios feitos com eles seguem abaixo: Este foi o processo de calibração de 3 sensores de condutividade elétrica usados para medir em "micro siemens" ou em "PPM" (partes por milhão) a quantidade de ions livres na solução, ou seja, a quantidade de sais minerais que são os nutrientes para a planta. 
Microfarms: análise da complexidade tecnológica e custos para a criação de microfazendas para produção de alimentos

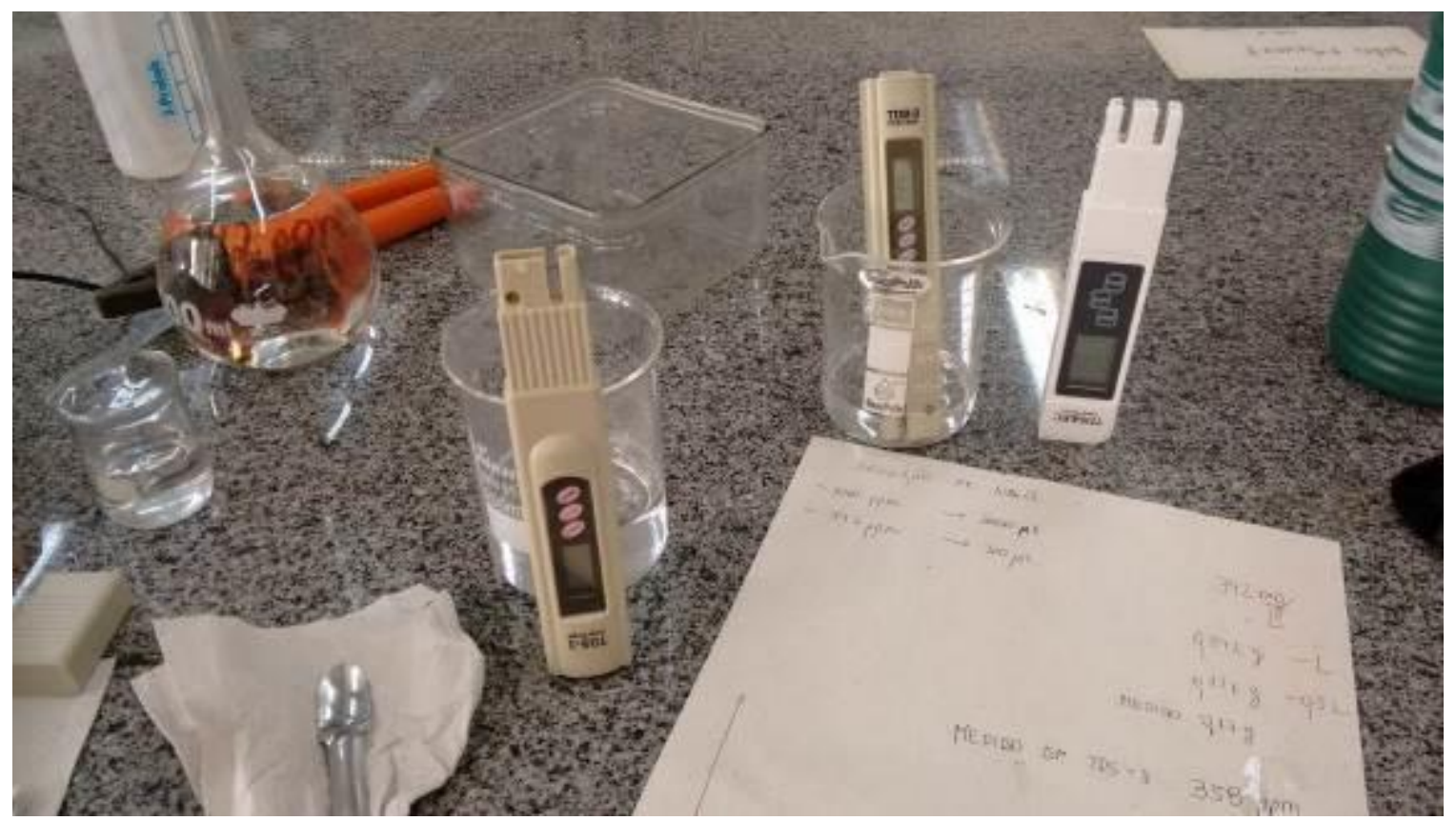

Ilustração 6 - Imagens dos sensores de condutividade elétrica. Fonte: elaborado pelos autores.

Dessa forma, como a compra de um sensor estava fora do escopo e das possibilidades deste trabalho foi criado um projeto para produção de um sensor em um trabalho futuro. $\mathrm{O}$ projeto segue abaixo.

Para medir a condutividade elétrica foi elencada a necessidade de um circuito chamado de "ponte de Wheatstone" que é um esquema elétrico que serve para a medição de uma resistência elétrica desconhecida, chamada de Rx (que no caso seria a resistência da água). Os componentes do circuito são uma fonte, um voltímetro (representado por $\mathrm{V}$ na imagem), e quatro resistores, sendo que o R2 é um potenciômetro (resistor com resistência variável). Para determinar a resistência de Rx, é necessário ajustar a resistência do potenciômetro até que a corrente no voltímetro seja zero.

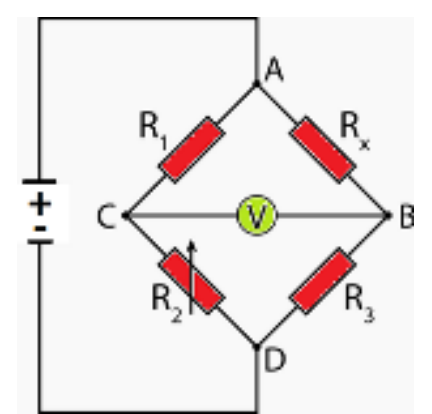

Ilustração 7 - Ponte de Wheatstone Fonte: elaborado pelos autores. 
Microfarms: análise da complexidade tecnológica e custos para a criação de microfazendas para produção de alimentos

Quando o voltímetro apontar zero, utilizando a expressão matemática R2/R1 = R3/Rx, a partir da medida de R2 é encontrado o valor da resistência Rx.

Visando facilitar a conversão dos sinais, dada a limitação do conhecimento de eletrônica dos membros do grupo de estudos, foi pesquisado no site Robotshop (2015) um shield (placa de encaixe) para Arduíno que realiza essa conversão, sendo apenas necessário montar o esquema normal da ponte de Wheatstone, ligar ele nesse shield e utilizar a biblioteca do shield para ver quanto é aquela resistência Rx. Este seria o método mais acessível para conseguir realizar a medição dadas as limitações do projeto e o protótipo e testes dessa solução ficam para trabalhos futuros.

Este sensor será acoplado próximo a válvulas de comando "solenóides" conforme as da imagem abaixo que podem ser acionadas via microcontrolares e/ou Arduíno para a medição da condutividade elétrica na água do sistema.

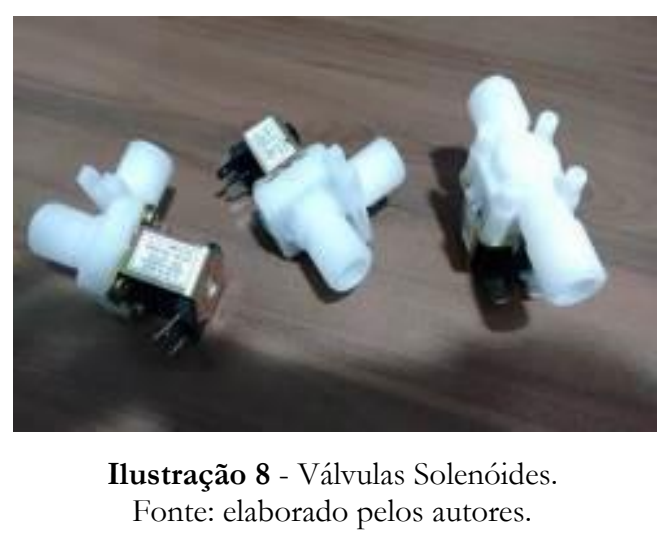

\section{Protótipo experimental}

Como a proposta inicial do projeto foi a criação de um protótipo e dada as limitações de recursos e conhecimento da equipe, foi proposto um protótipo para controle de duas variáveis fundamentais no projeto, a temperatura e a luminosidade. Para tanto os equipamentos e peças foram comprados com recursos próprios dos membros da equipe e doados ao projeto, conforme tabela abaixo:

\begin{tabular}{|c|l|c|}
\hline Item & \multicolumn{1}{|c|}{ Descrição } & Preço (R\$) \\
\hline 1 & 1 placa Arduíno UNO & 80,00 \\
\hline 2 & 1 Protoboard & 15,00 \\
\hline 3 & 1 cabo USB & 7,00 \\
\hline 4 & 1 fonte 220v para 12v. 2 amperes. & 25,00 \\
\hline 5 & 2 LED & 1,00 \\
\hline
\end{tabular}


Microfarms: análise da complexidade tecnológica e custos para a criação de microfazendas para produção de alimentos

\begin{tabular}{|c|l|c|}
\hline 6 & 1 Placa com dois relés de acionamento & 20,00 \\
\hline 7 & Resistores de 22kohms & 1,00 \\
\hline 8 & Resistores de 820ohms & 1,00 \\
\hline 9 & 1 Ds18b20 Impermeável (Sensor de temperatura) & 25,00 \\
\hline 10 & Fios de cobre. & 5,00 \\
\hline 11 & $\begin{array}{l}\text { 2 Lampadas LED Red/Blue (específica para crescimento de } \\
\text { plantas) 220v. }\end{array}$ & 40,00 \\
\hline 12 & Cabos e plugs & 20,00 \\
\hline 13 & Caixa Plástica & 18,00 \\
\hline 14 & 2 coolers/ventiladores (reaproveitados de computadores antigos) & $\mathbf{2 5 8 , 0 0}$ \\
\hline Total & & \\
\hline
\end{tabular}

Quadro 1 - Peças utilizadas em protótipo Fonte: elaborado pelos autores.

Com as peças descritas acima elaboramos o protótipo conforme abaixo. Este protótipo visa o controle da temperatura já que possui termômetro e ventiladores que são acionados quando o termômetro encontra temperaturas elevadas. Além disso, existe um sensor de luz que detecta a fraca presença do sol e assim aciona lâmpadas para permitir uma luminosidade maior no ambiente favorecendo o crescimento das plantas.

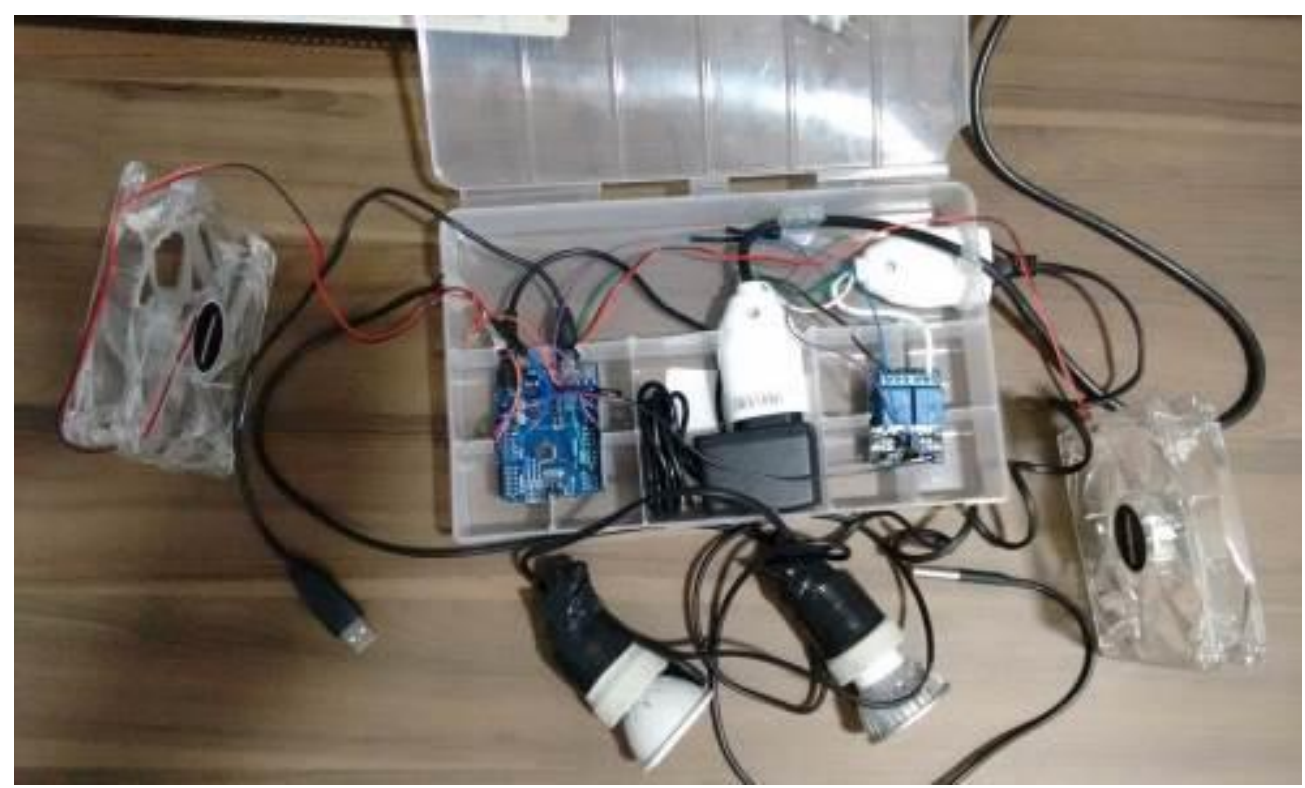

Ilustração 9 - Protótipo para controle de temperatura e luminosidade.

Fonte: elaborado pelos autores. 
Microfarms: análise da complexidade tecnológica e custos para a criação de microfazendas para produção de alimentos

No protótipo as lâmpadas são acionadas via relés pois o Arduíno trabalha apenas com uma tensão de $5 \mathrm{v}$ enquanto as lâmpadas precisam 220v. Dessa forma no relé recebe o controle de $5 \mathrm{v}$ e aciona a carga de $220 \mathrm{v}$ para as lâmpadas.

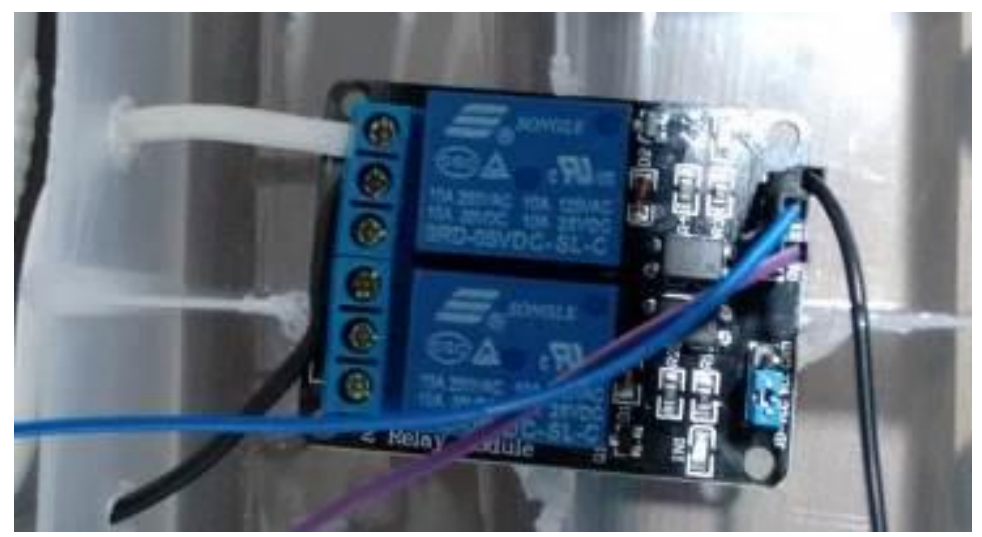

Ilustração 10 - Relés para acionamento das lâmpadas 220v. Fonte: elaborado pelos autores.

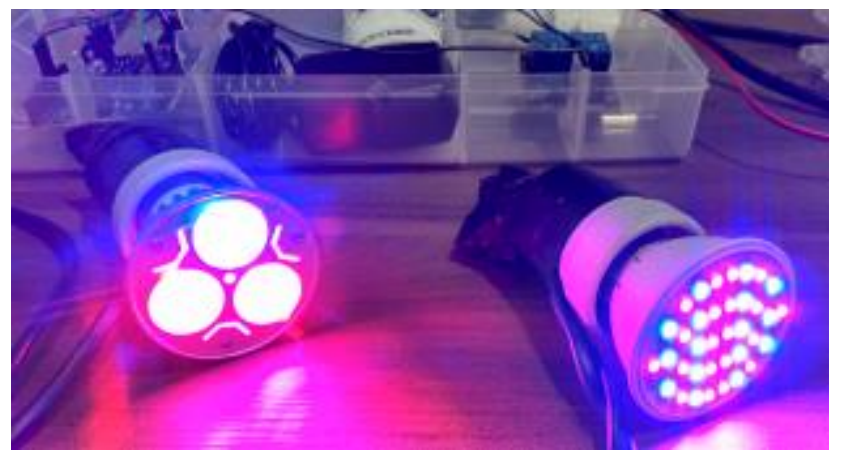

Ilustração 11 - Lâmpadas para crescimento de plantas possuem Leds azuis e vermelhos. Fonte: elaborado pelos autores.

Por fim, como resultados deste projeto temos ainda a apresentação de resumo e banner no evento científico "Semana de Ciência e Tecnologia - SECITEC" do Instituto Federal Catarinense - IFC, Campus Luzerna.

\section{CONSIDERAÇÕES FINAIS}

A equipe do projeto ficou surpreendida positivamente com os resultados alcançados. Apesar do projeto ser complexo de necessitar de um longo caminho de testes e validação para ser efetivamente considerado viável foi comprovado o baixo custo necessário para a criação da estrutura de uma microfazenda. O que reforça a possibilidade de criação contínua de melhorias e possibilidade de testes futuros. Além disso, as informações geradas com este trabalho podem ser 
Microfarms: análise da complexidade tecnológica e custos para a criação de microfazendas para produção de alimentos

utilizadas em projetos futuros colaborando com o arranjo produtivo local de produção de alimentos.

Por fim, agradecemos o Instituto Federal Catarinense - IFC, Campus Luzerna, pelo fomento à bolsa de iniciação científica proporcionados a este projeto via edital 05/2015 com recursos internos do campus.

\section{REFERÊNCIAS}

ARDUINO. What is ARDUINO?. Disponível em: <http://www.arduino.cc>. Acesso em: 14 de mar. 2015.

ALBERONI, Robson de Barros. Hidroponia: como instalar e manejar o plantio. São Paulo. 102 p. Nobel Editora, 1998.

ANALION. Célula de Condutividade C801/1 Constante K 1 120mm. Disponível em: $<$ http://www.analion.com.br/ecommerce_site/produto_7457_8124_Celula-de-CondutividadeC801-1-Constante-K-1-120mm\#esp>. Acesso em: 27 de mar. 2015.

DOUGLAS, James Sholto. Hidroponia: cultura sem terra. Tradução e prefácio Zilmar Ziller Marcos. São Paulo: Nobel Editora, 1987.

INOVALE. Polo de Inovação Vale do Rio do Peixe - Inovale. Disponível em: $<$ www.poloinovale.com.br>. Acesso em: 15 de mar. 2015.

FILIPEFLOP. Blog FilipeFlop. Controle Motor DC 12v com Arduíno Motor Shield L293D. Disponível em: <http://blog.filipeflop.com/motores-e-servos/controle-motor-dc-arduinomotor-shield.html>. Acesso em: 27 abr. 2015.

GLOBO ECOLOGIA. Até 2050, a produção mundial de alimentos deverá crescer $\mathbf{6 0} \%$. 2013. Disponível em: <http://redeglobo.globo.com/globoecologia/noticia/2013/06/ate-2050producao-mundial-de-alimentos-devera-crescer-60.html>. Acesso em: 15 de mar. 2015.

LABHIDRO. LabHidro Laboratório de Hidroponia. UFSC Universidade Federal de Santa Catarina. Disponível em: <http://www.labhidro.cca.ufsc.br>. Acesso em 27 abr. 2015.

LEGO. LEGO ${ }^{\circledR}$ MINDSTORMS ${ }^{\circledR}$ EV3! LEGO building system with the most advanced technology. Disponível em: <http://www.lego.com/enus/mindstorms/?domainredir=mindstorms.lego.com>. Acesso em: 16 de mar. 2015.

McROBERTS, Michael. Arduino Básico. 456 p. São Paulo: Novatec, 2011.

MONK, Simon. Projetos com Arduino e Android: Use seu Smartphone ou Tablet para Controlar. São Paulo: Bookman, 2014. 
Microfarms: análise da complexidade tecnológica e custos para a criação de microfazendas para produção de alimentos

MUNDOOSGANICO. Hidroponia não é orgânico. Disponível em: $<$ http://mundoorgnico.blogspot.com.br/2009/08/hidroponia-nao-e-organico.html $>$. Acesso 12/08/15.

ONU. Organização das Nações Unidas. “Agricultura, Saúde, Meio Ambiente: Unindo Esforços para o Bem-Estar dos Povos das Américas" é o tema da $16^{a}$ Reunião Ministerial. Disponível em: <http://nacoesunidas.org/fao-producao-de-alimentos-deve-levar-emconsideracao-impactos-das-mudancas-climaticas/>. Acesso em: 27 de jul. 2012.

ONU. Organização das Nações Unidas. FAO: Produção de alimentos deve levar em consideração impactos das mudanças climáticas. Disponível em: $<$ http:/ / nacoesunidas.org/fao-producao-de-alimentos-deve-levar-em-consideracao-impactosdas-mudancas-climaticas/>. Acesso em: 15 de mar. 2015.

POLO INOVALE. Polo de Inovação Vale do Rio do Peixe - Inovale. Disponível em: <www.poloinovale.com.br>. Acesso em: 15 de mar. 2015.

OSHW. Open Source Hardware (OSHW). Disponível em: <http://www.oshwa.org/>. Acesso em: 16 de mar. 2015.

RAPSBERRY. O que é RaspberryPi. Site Oficial. Disponível em: <http://www.raspberrypi.org>. Acesso em 15 de mar. 2015.

ROBOTSHOP. Wheatstone Shield \& LCD. Disponível em: <http://www.robotshop.com/blog/en/arduino-load-cell-lcd-17078>. Acesso em 30. nov. 2015. 